\title{
Work Satisfaction Levels of Music Therapists in the United States: A Mixed Methods Analysis
}

\author{
Anthony Meadows ${ }^{1 *}$, Lillian Eyre ${ }^{2}$, Audra Gollenberg ${ }^{1}$ \\ 1 Shenandoah University, Winchester, USA \\ 2 Temple University, Philadelphia, USA \\ *ameadows2@su.edu \\ Received: 6 June 2021 Accepted: 10 January 2022 Published: 1 March 2022 \\ Editor: Juanita Eslava-Mejia Reviewers: Annie Heiderscheit, Heather Wagner
}

\begin{abstract}
This mixed methods study reports levels of work satisfaction of music therapists working in the United States. A total of 1,154 board-certified music therapists completed a 28-question survey focused on their workplace, work, and professional development experiences, along with their levels of stress, burnout, and happiness. Two open-ended questions asked respondents to reflect on their identities as music therapists. Composite work satisfaction scores were subsequently divided into quartiles, characterizing high, moderate, and low work satisfaction groups. Music therapists reporting high work satisfaction indicated significantly higher levels of positive agreement with questions regarding work satisfaction than did music therapists reporting moderate or low work satisfaction. Work satisfaction was also significantly associated with stress, burnout, and happiness. The profiles of music therapists reporting high, moderate, and low work satisfaction were further connected to their identities as music therapists, illuminating the characteristics of music therapists who are thriving, those who are moderately satisfied at work, and those who are struggling. These profiles provide insights into the occupational wellbeing of the profession.
\end{abstract}

Keywords: levels of work satisfaction, stress, burnout, happiness, occupational wellbeing, identity, music therapists

\section{Introduction}

This article continues a line of research in which we examined the work lives of music therapists in the United States. In the first article from this research project (Meadows et al., 2022; companion article appearing in this issue), the workforce characteristics, workplace, and job satisfaction of 1,154 music therapists were described, along with their levels of stress, burnout, and happiness. These data revealed that, on the whole, these music therapists were happy with their workplace and job conditions and experienced moderate stress and low burnout. In addition, when asked about their overall professional happiness, $74 \%$ of respondents somewhat or completely agreed with 
the statement "I am happy at work," $83 \%$ somewhat or completely agreed with the statement "I am happy I became a music therapist," and 72\% somewhat or completely agreed with the statement "I believe I have a future in the profession." These findings provide an encouraging overall picture of the field, while also highlighting areas of concern that may provide opportunities to strengthen the overall health of the profession.

In our discussion of these findings, three specific areas were identified that warrant further investigation (Meadows et al., 2022). First, there appears to be disparate salaries paid to music therapists. While the average full-time salary of a music therapist $(\$ 53,634.59)$ provides an encouraging economic outlook, the average reported salary (full- and part-time) is $\$ 42,544.40$, and the average reported salary for a music therapist with less than 1 year of experience is $\$ 36,456.90$. Further, while 1,007 music therapists provided salary data, only 596 reported full-time salaries, or $59.19 \%$ of respondents. Additionally, of the 109 early-career music therapists (with less than 1 year of experience) who provided salary data, only $62(56.8 \%)$ reported full-time salaries. While these music therapists may have chosen to work part-time, responses to related survey questions suggest otherwise. When asked to respond to the statement "My music therapy income meets my basic needs," only $23.6 \%$ of respondents completely agreed and $34.2 \%$ somewhat agreed, while $18.7 \%$ somewhat disagreed and $15 \%$ completely disagreed. Further, when asked to rate their degree of satisfaction with their salary, only $17.5 \%$ were completely satisfied and $36.9 \%$ somewhat satisfied, while $27.7 \%$ were somewhat dissatisfied and $8.7 \%$ completely dissatisfied. This suggests that, on the whole, some music therapists have concerns about their salaries, and the extent to which this impacts their overall work experience is worthy of further examination.

Second, variations in job satisfaction, stress, burnout, and happiness call for further analysis (Meadows et al., 2022). Composite job satisfaction scores indicated that $66 \%$ of music therapists responded to a series of job satisfaction questions in ways that suggested a positive job experience, whereas $21 \%$ responded in ways that suggested the opposite. Composite workplace stress scores indicated that $52 \%$ of music therapists responded in ways that suggested they experienced low workplace stress, whereas $32 \%$ responded in ways that suggested the opposite. Composite burnout scores indicated that on average $61 \%$ of music therapists responded in ways that suggested they have low levels of burnout, whereas $23 \%$ responded in ways that suggest the opposite. Finally, composite happiness scores suggested that $73 \%$ of music therapists provided responses that indicated they were happy professionally (somewhat or completely), whereas $14 \%$ responded in ways that suggested they are unhappy.

Third, music therapists appear to have a broad range of professional development opportunities, including varied opportunities for career development (Meadows et al., 2022). While $56 \%$ of respondents somewhat or completely agreed with the statement "I have the same number of learning opportunities in my job that my colleagues do," $29 \%$ somewhat or completely disagreed with the statement. When participants were asked four questions regarding financial support and paid time off for continuing education (including conferences), the average level of agreement (somewhat or completely) was $43 \%$, whereas the average level of disagreement was $44 \%$ (somewhat or completely), suggesting that less than half of survey respondents received adequate support for professional development. Finally, when asked whether they had "opportunities for research at their job and the support to do so," $37 \%$ of music therapists somewhat or completely agreed, while $39 \%$ somewhat or completely disagreed.

When these job satisfaction, professional development, stress, burnout, and happiness data were examined as a whole, they suggested a range of work experiences that included music therapists who experienced high satisfaction in their work lives, those who experienced moderate satisfaction, and those who experienced low satisfaction. In this article, we differentiate these levels of work experience by quartiles, with the highest level of satisfaction attributed to the highest quartile of survey responses (top $25 \%)$, moderate satisfaction to the middle two quartiles (26\%-74\%), and low satis- 
faction to the lowest quartile (bottom 25\%). We then examine a range of variables in relation to these levels of satisfaction, seeking to define and differentiate each level.

In addition to examining differences in responses to categories of survey questions, we analyzed written responses to two questions regarding how respondents thought about being a music therapist ("When I think about being a music therapist, the first thing that comes to mind is...") and their identities as a music therapist ("When I think about my identity as a music therapist, the first thing that comes to mind is..."). Responses to these questions provide insight into how music therapists think about their professional identities, and differences in these responses illuminate core characteristics of these music therapists that may clarify the nature of the struggles some music therapists experience in relation to the overall quality of their work lives, while also illuminating the characteristics of those who are thriving professionally.

We propose that these data provide insight into the occupational wellbeing of our profession. Occupational wellbeing can be defined in a number of ways. Van Horn et al. (2004) defined occupational wellbeing as "a positive evaluation of various aspects of one's job, including affective, motivational, behavioral, cognitive and psychosomatic dimensions" (p. 366). Taking a different perspective, Doble and Caron Santha (2008) suggested that occupational wellbeing occurs when individuals have the opportunity to engage in a variety of occupations that foster meaning and satisfaction. According to these authors, occupational wellbeing has several prerequisites or intrinsic needs, which they refer to as occupational needs. These needs include experiences of agency (a sense of control over how and when one engages in their occupation), accomplishment (feelings of mastery), affirmation (praise and acknowledgment), pleasure (fun), renewal (rest and relaxation), coherence (connecting one to their past, present, and future), and companionship (closeness and connection to others).

Through an examination of the characteristics of each level of work satisfaction, our aim is to define and differentiate these levels, contextualizing these data according to various components of occupational wellbeing. In so doing, we seek to define and differentiate levels of occupational wellbeing and to consider these dimensions as indictors of occupational identity (Skorikov \& Vondracek, 2011).

\section{Method}

\section{Participants}

Detailed demographic data along with the workforce characteristics of survey participants can be found in Meadows et al. (2022). In total, 1,154 music therapists completed some or all of the survey questions, a $14.59 \%$ response rate. Participants were predominantly female (88.2\%), and their age reflected a bimodal distribution, with most ages between 20 and 29 years (36.7\%) and 30 and 39 years (30.3\%). All seven regions of the American Music Therapy Association were represented, with the majority of participants from the mid-Atlantic (27.7\%) and Great Lakes (24.7\%) regions. Further, 56.83\% of respondents were members of the American Music Therapy Association.

\section{Ethical Approval}

This study was reviewed by the Shenandoah University Institutional Review Board (protocol \#752) and was adjudicated as exempt from further review.

\section{Survey Design}

The survey consisted of 25 multiple-choice and three open-ended questions. The multiple-choice questions related to demographic information (17 questions), workplace satisfaction (1 question; 7 items), professional development (1 question; 6 items), job satisfaction (4 questions; 11 items), stress (1 question; 11 items), burnout (1 question; 16 items), and happiness ( 1 question; 7 items). Participants were also asked to write 
in their exact salary. In addition, at the end of the survey, they were invited to provide written responses to two open-ended questions: "When I think about being a music therapist, the first thing that comes to mind is..." and "When I think about my identity as a music therapist, the first thing that comes to mind is...."

Further details regarding survey construction and distribution can be found in Meadows et al. (2022).

\section{Data Analysis}

Data analysis occurred in three phrases, consistent with an explanatory mixed methods design (Burns \& Masko, 2016). First, survey responses were categorized and examined according to level of work satisfaction. Second, written responses to two open-ended questions were analyzed using methods consistent with thematic analysis. Third, qualitative and quantitative data were then combined to provide a comprehensive picture of the levels of work satisfaction. Each phase is described in further detail below.

\section{Quantitative Analysis}

Composite scores for happiness, burnout, stress, and work satisfaction were calculated by summing the reported values for each question in their respective domain. To allow for internal comparisons between groups of music therapists, quartiles of scores were created for each domain. A chi-squared test for significance was utilized when comparing the distribution of categorical variables. Correlation between individual job satisfaction questions and composite satisfaction scores were determined using Spearman correlations. All statistical analyses were completed using SAS University Edition software (version 9.2).

\section{Qualitative Analysis}

Open-ended responses to two survey questions were analyzed according to level of work satisfaction. These analyses were based on an inductive approach to thematic analysis using the question itself as a first cycle coding method. Second cycle coding methods focused on pattern coding to compare the similarities, differences, and frequencies of responses (Saldaña, 2016, p. 236) and on values coding to identify attitudes, values, and beliefs (Saldaña, 2016, p. 131). Simultaneous coding was applied to analyze the valence of each code (negative, positive, neutral, or mixed), thereby indicating the range and complexity of responses (Saldaña, 2016, p. 83).

After becoming familiar with the responses as a whole, the first and second authors then analyzed each question using the following steps: 1) each response statement was coded according to patterns and/or values, 2) each code was simultaneously assigned a valence, 3 ) these codes were reduced in number by combining codes with similar constructs and distributions of valences in order to create categories, 4) categories were combined to create themes and were evaluated for accuracy by returning to the original data to determine goodness of fit, and 5) each theme was then characterized in narrative form, providing an overall description of these themes according to level of work satisfaction. See Appendix A for coding rules, including details of how data such as "mixed" responses were analyzed.

\section{Mixing Data}

High, moderate, and low work satisfaction profiles were then developed by combining quantitative and qualitative data into a narrative form. This included combining survey responses and qualitative themes that characterize each level of work satisfaction and then examining satisfaction levels according to their similarities and differences. Finally, satisfaction levels were examined according to the characteristics associated with professional identity and occupational wellbeing (Doble \& Caron Santha, 2008). 


\section{Results}

Total work satisfaction scores were calculated by combining responses to two questions regarding workplace satisfaction, job satisfaction, and professional development (24 items). Total scores were then divided into quartiles to differentiate levels of work satisfaction. Music therapists who scored in the highest quartile $(n=246)$ were characterized as having high work satisfaction, those in the middle two quartiles moderate satisfaction $(n=447)$, and those in the lowest quartile low satisfaction $(n=240)$. The characteristics of music therapists in each quartile were then examined in a variety of ways to understand more about the attributes of each group.

\section{Characteristics of High, Moderate, and Low Work Satisfaction}

Music therapists in the highest quartile of work satisfaction reported significantly higher levels of positive agreement with questions regarding work satisfaction than did music therapists in the middle $(p<0.0001)$ and lowest quartiles of work satisfaction $(p$ $<0.0001)$. That is, when taken as a whole, music therapists in the highest quartile of work satisfaction reported more satisfying work conditions, greater work satisfaction, and more satisfying professional development opportunities than did those in the middle and lowest quartiles. Music therapists in the moderate satisfaction group tended to report moderate agreement, albeit with some variation, with questions related to workplace and job satisfaction, but had significantly higher satisfaction than did those in the lowest quartile group $(p<0.0001)$. However, when each of the survey questions was examined to determine the extent to which it was uniquely associated with a level of work satisfaction, each question was significantly associated with the workplace satisfaction composite score $(p<0.0001)$. Further, each question had a moderate correlation with the composite score, with a range of Spearman correlation coefficients from 0.4 to $0.6(p<0.0001)$. This suggests that while a complex constellation of factors were associated with work satisfaction levels, as represented in the 24 questions associated with work satisfaction, each of these factors was of equal importance in understanding work satisfaction. Table 1 provides a summary of the distribution of scores for each work satisfaction level. Lower scores equate to higher satisfaction.

\section{Relationship Between Work Satisfaction and Demographic Variables}

Overall, male music therapists were more likely than female music therapists to be categorized in the high work satisfaction quartile $(p=0.01)$. There were no differences in work satisfaction levels by age $(p=0.48)$, race/ethnicity $(p=0.44)$, degree $(p=$ $0.07)$, years working as a music therapist $(p=0.28)$, or years in current position $(p=$ $0.11)$.

Work satisfaction was impacted by the settings in which these music therapists worked. Music therapists working in medical settings, universities and colleges, hospice, and "other" (a composite work category) were more likely to be categorized in the highest quartile of satisfaction. Conversely, music therapists working in older adult/long-term care communities, in mental health settings, and as self-employed/ private practice or community music therapists, were more likely to fall in the lowest quartile of satisfaction $(p<0.0001)$. Table 2 provides a summary of the distribution of music therapists in each quartile by work setting.

Annual salary was also associated with work satisfaction. Music therapists reporting the highest work satisfaction were more likely to report annual salaries greater than $\$ 45,000.00(p<0.0001)$. In fact, $42 \%$ of music therapists who reported salaries in the $\$ 60,000.00-\$ 75,000.00$ range and $58 \%$ of music therapists who reported salaries greater than $\$ 75,000.00$ reported the highest work satisfaction. Conversely, music therapists who reported the lowest work satisfaction also reported the lowest salaries. In fact, $51 \%$ of music therapists who reported salaries below $\$ 10,000.00$ and $47 \%$ of music therapists who reported salaries in the $\$ 10,000.00-\$ 20,000.00$ range reported the lowest work satisfaction. 


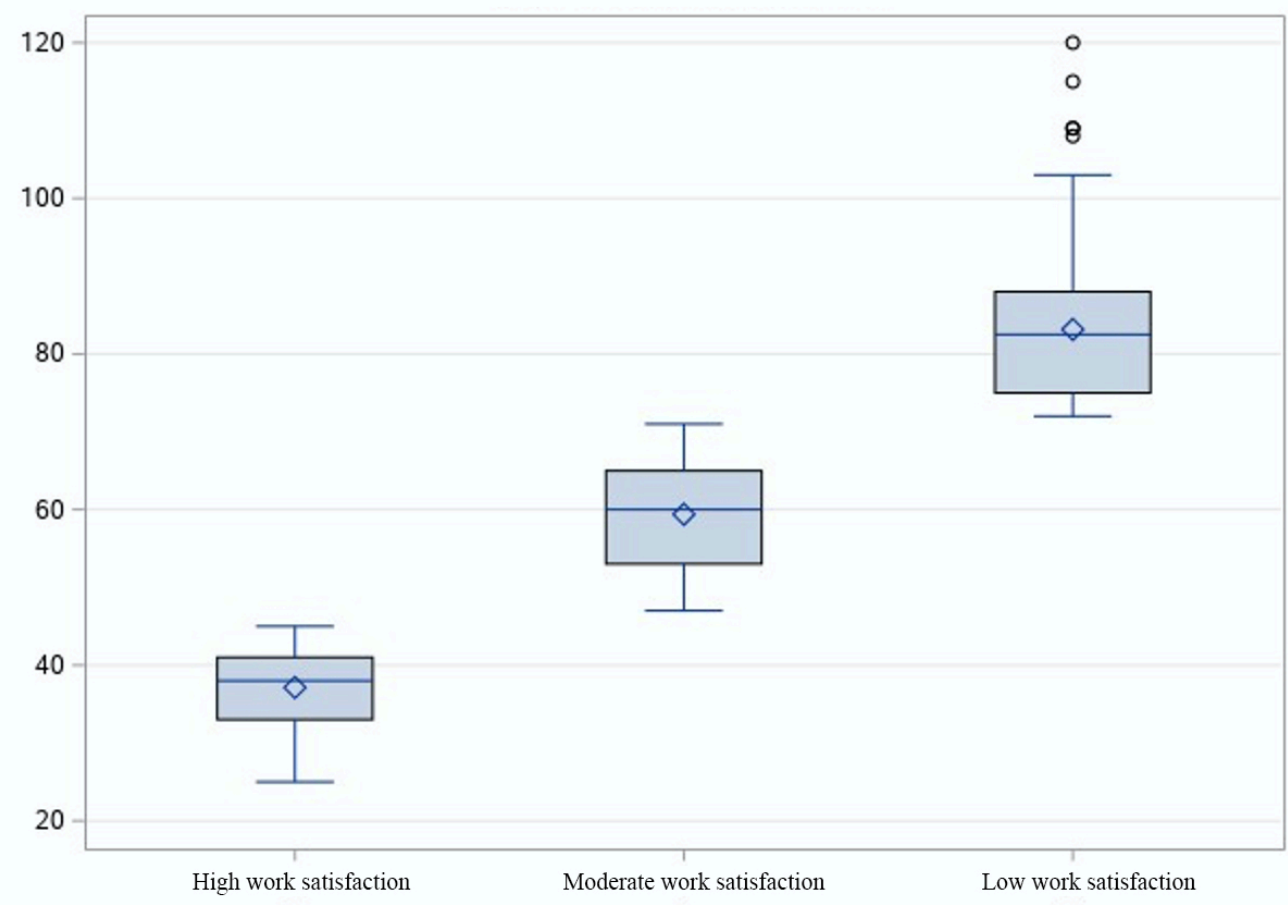

Table 1

Distribution of Composite Work Satisfaction Scores by Level of Satisfaction

Table 2

Levels of Work Satisfaction by Setting

\begin{tabular}{|c|c|c|c|c|c|c|c|c|}
\hline \multirow[t]{2}{*}{ Setting } & \multicolumn{2}{|c|}{$\begin{array}{l}\text { High Work } \\
\text { Satisfaction }\end{array}$} & \multicolumn{2}{|c|}{$\begin{array}{l}\text { Moderate Work } \\
\text { Satisfaction }\end{array}$} & \multicolumn{2}{|c|}{$\begin{array}{l}\text { Low Work } \\
\text { Satisfaction }\end{array}$} & \multicolumn{2}{|c|}{ Total } \\
\hline & $n$ & $\%$ & $n$ & $\%$ & $n$ & $\%$ & $n$ & $\%$ \\
\hline Children's facilities and schools & 36 & 27.7 & 65 & 50 & 29 & 22.3 & 130 & 14.0 \\
\hline Community music therapy & 9 & 23.7 & 18 & 47.7 & 11 & 29.0 & 38 & 4.1 \\
\hline $\begin{array}{l}\text { Older adult/long-term care commu- } \\
\text { nities }\end{array}$ & 9 & 12.7 & 39 & 54.9 & 23 & 32.4 & 71 & 7.6 \\
\hline Hospice & 30 & 30.6 & 46 & 46.9 & 22 & 22.5 & 98 & 10.5 \\
\hline Medical settings & 39 & 48.2 & 36 & 44.4 & 6 & 7.4 & 81 & 8.7 \\
\hline $\begin{array}{l}\text { Mental health, including addiction } \\
\text { treatment }\end{array}$ & 25 & 17.7 & 71 & 50.4 & 45 & 31.9 & 141 & 15.1 \\
\hline Self-employed/private practice & 42 & 21.8 & 95 & 49.2 & 56 & 29.0 & 193 & 20.7 \\
\hline Universities/colleges & 11 & 33.3 & 14 & 42.4 & 8 & 24.4 & 33 & 3.5 \\
\hline Other & 45 & 30.6 & 62 & 42.2 & 40 & 27.2 & 147 & 15.8 \\
\hline
\end{tabular}

Concomitantly, work satisfaction was associated with income satisfaction. Music therapists with high work satisfaction reported higher levels of income satisfaction, and these satisfaction levels were significantly different from those of music therapists who reported low work satisfaction $(p<0.0001)$. In fact, $54 \%$ of music therapists who completely agreed with the statement "I am satisfied with my music therapy income" also reported the highest work satisfaction, whereas 51\% of music therapists who completely disagreed with this statement reported the lowest work satisfaction. Additionally, $47 \%$ of music therapists who completely agreed with the statement "My 
Table 3

Levels of Work Satisfaction, Stress, Burnout, and Happiness

\begin{tabular}{|c|c|c|c|c|c|c|c|c|}
\hline \multirow[t]{2}{*}{$\begin{array}{l}\text { Wellbeing } \\
\text { Measure }\end{array}$} & \multicolumn{2}{|c|}{$\begin{array}{l}\text { High Work } \\
\text { Satisfaction }\end{array}$} & \multicolumn{2}{|c|}{$\begin{array}{l}\text { Moderate Work } \\
\text { Satisfaction }\end{array}$} & \multicolumn{2}{|c|}{$\begin{array}{l}\text { Low Work } \\
\text { Satisfaction }\end{array}$} & \multicolumn{2}{|c|}{ Total } \\
\hline & $n$ & $\%$ & $n$ & $\%$ & $n$ & $\%$ & $n$ & $\%$ \\
\hline \multicolumn{9}{|l|}{ Stress* } \\
\hline Low & 120 & 58.5 & 75 & 36.6 & 10 & 4.9 & 205 & 23.2 \\
\hline Moderate & 96 & 23.0 & 223 & 53.4 & 99 & 23.7 & 418 & 47.3 \\
\hline High & 17 & 6.5 & 122 & 46.7 & 122 & 46.7 & 261 & 29.5 \\
\hline \multicolumn{9}{|l|}{ Burnout* } \\
\hline Low & 141 & 69.5 & 57 & 28.1 & 5 & 2.5 & 203 & 29.6 \\
\hline Moderate & 83 & 19.8 & 262 & 62.5 & 74 & 17.7 & 380 & 43.2 \\
\hline High & 3 & 1.2 & 92 & 37.3 & 152 & 61.5 & 239 & 27.2 \\
\hline \multicolumn{9}{|l|}{ Happiness* } \\
\hline Low & 19 & 8.0 & 100 & 41.8 & 261 & 29.5 & 260 & 29.6 \\
\hline Moderate & 90 & 23.7 & 198 & 53.4 & 99 & 23.7 & 380 & 43.2 \\
\hline High & 125 & 48.1 & 117 & 45.0 & 18 & 6.9 & 239 & 27.2 \\
\hline
\end{tabular}

music therapy income meets my basic financial needs" were also identified as having the highest work satisfaction, whereas $62 \%$ of music therapists who completely disagreed with this statement were identified as having the lowest work satisfaction.

Finally, work satisfaction was also associated with satisfaction with hours worked $(p$ $<0.0001)$. When asked to indicate their level of satisfaction with their hours worked, $37 \%$ of music therapists who indicated they were completely satisfied reported the highest level of work satisfaction. Conversely, $62 \%$ who indicated they were completely unsatisfied reported the lowest level of work satisfaction.

\section{Work Satisfaction, Stress, Burnout, and Happiness}

Not surprisingly, work satisfaction was associated with stress, burnout, and happiness $(p<0.0001)$. Music therapists reporting the highest work satisfaction reported the lowest levels of stress and burnout and the highest levels of happiness. Conversely, music therapists reporting the lowest work satisfaction reported the highest levels of stress and burnout and the lowest levels of happiness. Table 3 provides a summary.

Music therapists reporting high work satisfaction $(n=246)$ had the following profile related to stress, burnout, and happiness: $52 \%$ reported low levels of stress, $62 \%$ reported low levels of burnout, and 53\% reported high levels of happiness. In contrast, $7 \%$ reported high levels of stress, $1 \%$ reported high levels of burnout, and $8 \%$ reported low levels of happiness.

Music therapists reporting moderate work satisfaction $(n=447)$ had the following profile related to stress, burnout, and happiness: $18 \%$ reported low levels of stress, $14 \%$ reported low levels of burnout, and 28\% reported high levels of happiness. In contrast, $29 \%$ reported high levels of stress, $22 \%$ reported high levels of burnout, and $24 \%$ reported low levels of happiness.

Music therapists reporting low work satisfaction $(n=240)$ had the following profile related to stress, burnout, and happiness: $4 \%$ reported low levels of stress, $2 \%$ reported low levels of burnout, and $8 \%$ reported high levels of happiness. In contrast, $53 \%$ reported high levels of stress, $66 \%$ reported high levels of burnout, and 52\% reported low levels of happiness. 


\section{Work Satisfaction and "Being a Music Therapist"}

In addition to examining differences in responses to categories of survey questions, we analyzed written responses to two questions regarding how respondents think about being a music therapist ("When I think about being a music therapist, the first thing that comes to mind is...") and their identities as a music therapist ("When I think about my identity as a music therapist, the first thing that comes to mind is...") in relation to their level of job satisfaction. These data provide additional insight into the overall wellbeing of these music therapists, illuminating core characteristics of their professional identities. Tables 4 and 5 provide a summary of the major themes related to each of these questions.

\section{Highly Satisfied Music Therapists}

When highly satisfied music therapists $(n=207)$ were asked to think about the first thing that comes to mind regarding being a music therapist, $77.8 \%$ (161) of their responses were positive, $7.8 \%$ (16) were negative, $10 \%$ (20) were mixed, and $4.8 \%$ (10) were neutral. Positive responses related to helping others (32\%), being grateful (9\%) finding the job enjoyable and rewarding (8.7\%), experiencing pride and passion (8.2\%), and finding satisfaction and fulfillment (8.2\%). These music therapists also noted music and creativity (6.3\%) as positive elements of being a music therapist. Negative responses related to being misunderstood and constantly needing to advocate for the profession (4.8\%). Having to advocate for the profession was also reported in mixed responses (3.4\%). Other mixed responses tended to focus on challenges associated with low salaries (4.8\%) and fewer job opportunities (2.4\%). For these respondents, their work as music therapists was unique and fulfilling, but this was tempered by these challenges, along with concerns about administrative load and feeling frustrated, under-appreciated, and under-represented.

\section{Moderately Satisfied Music Therapists}

When moderately satisfied music therapists $(n=373)$ were asked to think about the first thing that comes to mind regarding being a music therapist, $64.3 \%$ (240) of their responses were positive, $16.4 \%$ (61) were negative, $8.6 \%$ (32) were mixed, and $10.7 \%$ (40) were neutral. Positive responses related to helping others (27\%) and feeling fulfillment $(11.8 \%)$, passion and pride $(10.7 \%)$, and gratitude $(5.4 \%)$. Negative responses related to salaries (3.5\%), challenges (2.9\%), limitations and disappointment (2.7\%), and advocacy (2.7\%). Mixed responses related to challenges (3.5\%), feeling misunderstood (1.9\%), and salaries (1.6\%). Neutral responses (7\%) related to the profession as a whole, with no discernable valence. These responses included comments related to one's position, job tasks, and identification with a particular approach or population.

\section{Music Therapists with Low Satisfaction}

When music therapists with low satisfaction $(n=211)$ were asked to think about the first thing that comes to mind regarding being a music therapist, $43.6 \%$ (92) of their responses were negative, $40.3 \%$ (85) were positive, $10 \%(21)$ were mixed, and $6.2 \%$ (13) were neutral. Negative responses related to feeling misunderstood, having to constantly advocate for themselves and the profession, and questioning the value of music therapy (13.7\%). These music therapists also expressed concerns about their salaries (8.5\%) and a range of challenges (6.6\%) that included how hard the work was, inadequate to hostile work environments, and few opportunities for advancement. Positive responses related to helping others (18\%); gratitude, fulfillment, and pride (12.8\%); and enjoyment and excitement (7.1\%). Mixed responses, which included combinations of positive and negative responses, focused primarily on salaries (4.3\%), challenges (3.3\%), and feeling misunderstood and undervalued (1.9\%). Neutral responses (6.2\%) were related to professional issues and had no discernable valence. When the negative 
and mixed response data were combined, three themes were reaffirmed: feeling misunderstood (15.6\%), concerns about salaries (12.8\%), and challenges (10\%).

\section{Work Satisfaction and Professional Identity}

\section{Highly Satisfied Music Therapists}

When highly satisfied music therapists $(n=205)$ were asked to think about the first thing that comes to mind regarding their identity as a music therapist, $65.9 \%$ (135) of their responses were positive, 9.2\% (19) were negative, 9.8\% (20) were mixed, and $15.1 \%$ (31) were neutral. Positive responses included pride (e.g., pride in one's work and the profession; 12.2\%), gratitude and fulfillment (e.g., having a career and job that one loves; $12.2 \%$ ), value (e.g., unique benefits of music therapy; $8.3 \%$ ), and good fit (e.g., loving to work creatively with clients; 8.3\%). Negative responses included the interconnection of feeling misunderstood, advocacy, and recognition (e.g., dealing with people's misconceptions about music therapy; 5.4\%) and challenges and self-doubt (e.g., work-life balance being difficult to find because of overwhelming workload; 3.9\%). Mixed responses echoed the negative responses: challenge and isolation (e.g., loving and finding value in the job but being concerned about burnout and lack of opportunities for advancement; 2.9\%) and misunderstood and recognition (e.g., feeling respected by clients, but also misunderstood; 1.5\%). Neutral responses focused on professional role and clinical approach (e.g., identification with one's approach or client group; 6.3\%).

\section{Moderately Satisfied Music Therapists}

When moderately satisfied music therapists $(n=363)$ were asked to think about the first thing that comes to mind regarding their identity as a music therapist, $63.4 \%$ (230) of their responses were positive, $17.4 \%$ (63) were negative, $13.8 \%$ (50) were mixed, and 5.5\% (20) were neutral. The highest positive responses were pride (e.g., pride in the work one does and the clients one serves; 15.7\%); approach (e.g., identification with a particular approach one uses-for example, humanistic, music-centered, psychotherapeutic, or neurological; 7.4\%); helper (e.g., being in service of others; 7.2\%); and a combination of role, professional, and competent (e.g., the competence one has developed working with a particular population; 6.9\%). The highest negative response was a combination of misunderstood and limitation (e.g., a primarily negative association with one's identity based on belonging to a profession that is misunderstood and perceived as limited; 9.6\%), while the highest mixed responses focused on disidentification with music therapy (e.g., while being grateful for the knowledge gained through education and clinical experience, not self-identifying primarily as a music therapist; 2.8\%) and challenges and burnout (e.g., loving and being proud of one's work but being concerned with professional issues such as exhaustion and burnout; $2.2 \%$ ). Neutral responses focused primarily on being unsure (e.g., feeling uncertain, unclear, undecided, or in the process of forming their identity; $3.9 \%$ ).

\section{Music Therapists with Low Satisfaction}

When music therapists with low satisfaction $(n=206)$ were asked to think about the first thing that comes to mind regarding their identity as a music therapist, $40.3 \%$ (83) of their responses were positive, $32.5 \%$ (67) were negative, $18.9 \%$ (39) were mixed, and $8.3 \%$ (17) were neutral. The highest positive responses included pride and passion (e.g., pride in the work music therapists do with their clients; 9.2\%), role (e.g., identification primarily with one's role as a helper, therapist, supervisor, or educator; $6.8 \%$ ), good fit (e.g., that one's job is one's destiny or purpose in life; 5.8\%), and gratitude and fulfillment (e.g., gratitude for being able to help others through music and relationships; 4.9\%). Negative responses focused on feeling misunderstood (e.g., being perceived as an entertainer, a volunteer, a music teacher, the "music lady," or a "joke"; 12.1\%); the interconnection between self-doubt, shame, failure, and regret (e.g., feeling inadequate and insecure about one's knowledge and clinical contribution in the workplace; 
Table 4

"When I think about being a music therapist, the first thing that comes to mind is..."

\begin{tabular}{|c|c|}
\hline Level of Satisfaction & $\%$ \\
\hline \multicolumn{2}{|l|}{ High Work Satisfaction $(n=207)$} \\
\hline \multicolumn{2}{|l|}{ Positive } \\
\hline Helping others & 32.0 \\
\hline Being grateful & 9.0 \\
\hline Enjoyable and rewarding & 8.7 \\
\hline Experiencing pride and passion & 8.2 \\
\hline Satisfaction and fulfillment & 8.2 \\
\hline Creativity & 6.3 \\
\hline \multicolumn{2}{|l|}{ Negative } \\
\hline Advocating for the profession and being misunderstood & 4.8 \\
\hline \multicolumn{2}{|l|}{ Mixed } \\
\hline Advocating for the profession and being misunderstood & 3.4 \\
\hline Salaries & 4.8 \\
\hline Fewer job opportunities & 2.4 \\
\hline \multicolumn{2}{|l|}{ Moderate Work Satisfaction $(n=373)$} \\
\hline \multicolumn{2}{|l|}{ Positive } \\
\hline Helping others & 27.0 \\
\hline Fulfillment & 11.8 \\
\hline Passion and pride & 10.7 \\
\hline Gratitude & 5.4 \\
\hline \multicolumn{2}{|l|}{ Negative } \\
\hline Salaries & 3.4 \\
\hline Challenges & 2.9 \\
\hline Limitations and disappointment & 2.7 \\
\hline Advocacy & 2.7 \\
\hline \multicolumn{2}{|l|}{ Mixed } \\
\hline Challenges & 3.5 \\
\hline Feeling misunderstood & 1.9 \\
\hline Salaries & 1.6 \\
\hline \multicolumn{2}{|l|}{ Low Work Satisfaction $(n=211)$} \\
\hline \multicolumn{2}{|l|}{ Positive } \\
\hline Helping others & 18.0 \\
\hline Gratitude, fulfillment, and pride & 12.8 \\
\hline Enjoyment and excitement & 7.1 \\
\hline \multicolumn{2}{|l|}{ Negative } \\
\hline Misunderstood, advocate, and questioning the value of music therapy & 13.7 \\
\hline Salaries & 8.5 \\
\hline Challenges & 6.6 \\
\hline Mixed & \\
\hline
\end{tabular}




\begin{tabular}{|l|l|}
\hline \multicolumn{1}{|c|}{$\quad$ Level of Satisfaction } & $\%$ \\
\hline Salaries & 4.3 \\
\hline Challenges & 3.3 \\
\hline Feeling misunderstood & 1.9 \\
\hline
\end{tabular}

6.8\%); and the combination of disidentification with music therapy and the belief that the profession needs to change (e.g., not identifying or no longer identifying as a music therapist; 6.8\%). Mixed responses focused on challenges (e.g., having few professional opportunities or feeling burned out and exhausted; 4.9\%) and advocacy (e.g., although clinical work is enjoyable, it requires constant advocacy, sometimes leading to exhaustion; 4.4\%). Neutral responses focused primary on feeling unsure (e.g., unsure of one's identity; 2.4\%).

\section{Discussion}

When the high, moderate, and low work satisfaction levels of music therapists were examined, three distinct profiles emerged. Highly satisfied music therapists reported more satisfying work conditions, greater work satisfaction, and more satisfying professional development opportunities than did music therapists who reported moderate or low satisfaction. Concomitantly, moderately satisfied music therapists reported more satisfying work conditions, greater work satisfaction, and more satisfying professional development opportunities than did music therapists who reported low satisfaction. Differences in overall satisfaction were also associated with salaries, income satisfaction, and satisfaction with hours worked, with highly satisfied music therapists reporting significantly higher levels of satisfaction when compared to music therapists with moderate and low satisfaction. A comparable difference was also evident between music therapists with moderate and low satisfaction.

\section{Workplace Satisfaction}

Importantly, no single workplace or job satisfaction question was uniquely associated with satisfaction levels, suggesting that each question is of equal importance for understanding work satisfaction. Table 6 presents differences in responses to questions associated with workplace satisfaction. Response distributions reveal important differences in levels of agreement (somewhat or complete agreement) with survey questions, especially with regards to questions that focus on budget, space, and session interruptions. In addition, only $47.92 \%$ of music therapists with low satisfaction reported somewhat or completely agreeing with the statement "I have access to the instruments I need for my music therapy sessions," suggesting a fundamental challenge for some music therapists in providing music experiences during their sessions.

A similar distribution of responses was evident when questions associated with job satisfaction were examined, as presented in Table 7. Highly satisfied music therapists reported high levels of agreement with each question, except for the two supervision questions, which gained moderate levels of agreement. Moderately satisfied music therapists reported moderate levels of agreement with each job satisfaction question, except for questions related to music therapy or creative arts therapy supervision, which gained a level of agreement of only $34.55 \%$. Music therapists with low satisfaction reported moderate to low levels of agreement with each question, with particularly low levels of agreement concerning team meetings and supervision. These differences highlight the characteristics of highly satisfying jobs, while also indicating the importance of increasing supervision opportunities and opportunities for music therapists to meaningfully contribute to team meetings. Access to music therapy/creative arts therapy supervision appears to be an important consideration for employers and policy makers. Lack of access to music therapy or creative arts therapy supervision may inhibit the professional development of a music therapist and may be negatively 
Table 5

"When I think about my identity as a music therapist, the first thing that comes to mind is..."

\begin{tabular}{|c|c|}
\hline First Thing That Comes to Mind & $\%$ \\
\hline \multicolumn{2}{|l|}{ High Work Satisfaction } \\
\hline \multicolumn{2}{|l|}{ Positive } \\
\hline Pride & 12.2 \\
\hline Gratitude and fulfillment & 12.2 \\
\hline Good fit & 8.3 \\
\hline Value & 7.3 \\
\hline \multicolumn{2}{|l|}{ Negative } \\
\hline Feeling misunderstood, advocacy, and recognition & 5.4 \\
\hline Challenges and self-doubt & 3.9 \\
\hline \multicolumn{2}{|l|}{ Mixed } \\
\hline Challenge and isolation & 2.9 \\
\hline Feeling misunderstood and recognition & 1.5 \\
\hline \multicolumn{2}{|l|}{ Moderate Work Satisfaction } \\
\hline \multicolumn{2}{|l|}{ Positive } \\
\hline Pride & 15.7 \\
\hline Approach & 7.4 \\
\hline Helper & 7.2 \\
\hline Role, professional, and competent & 6.9 \\
\hline \multicolumn{2}{|l|}{ Negative } \\
\hline Feeling misunderstood and limitations & 9.6 \\
\hline \multicolumn{2}{|l|}{ Mixed } \\
\hline Disidentification with music therapy & 2.8 \\
\hline Challenges and burnout & 2.2 \\
\hline \multicolumn{2}{|l|}{ Low Work Satisfaction } \\
\hline \multicolumn{2}{|l|}{ Positive } \\
\hline Pride and passion & 9.2 \\
\hline Role & 6.8 \\
\hline Good fit & 5.8 \\
\hline Gratitude and fulfillment & 4.9 \\
\hline \multicolumn{2}{|l|}{ Negative } \\
\hline Feeling misunderstood & 12.1 \\
\hline Self-doubt, shame, failure, and regret & 6.8 \\
\hline Disidentification with music therapy and belief that the profession needs to change & 6.8 \\
\hline \multicolumn{2}{|l|}{ Mixed } \\
\hline Challenges & 4.9 \\
\hline Advocacy & 4.4 \\
\hline
\end{tabular}


Table 6

Levels of Agreement with Specific Workplace Satisfaction Questions

\begin{tabular}{|c|c|c|c|}
\hline Workplace Satisfaction Question & $\begin{array}{l}\text { High Work } \\
\text { Satisfaction } \\
(n=242)\end{array}$ & $\begin{array}{l}\text { Moderate Work } \\
\text { Satisfaction } \\
\quad(n=437)\end{array}$ & $\begin{array}{l}\text { Low Work } \\
\text { Satisfaction } \\
(n=240)\end{array}$ \\
\hline "I am generally happy with my work conditions" & $\begin{array}{l}98.35 \% \\
(238)\end{array}$ & $\begin{array}{l}84.21 \% \\
(368)\end{array}$ & $\begin{array}{l}46.67 \% \\
(112)\end{array}$ \\
\hline $\begin{array}{l}\text { "I am allocated an adequate budget to carry out } \\
\text { my duties" }\end{array}$ & $\begin{array}{l}91.32 \% \\
(232)\end{array}$ & $\begin{array}{l}56.75 \% \\
(248)\end{array}$ & $\begin{array}{l}17.92 \% \\
(43)\end{array}$ \\
\hline $\begin{array}{l}\text { "I have appropriate space allocated to me for my } \\
\text { music therapy sessions" }\end{array}$ & $\begin{array}{l}90.50 \% \\
(219)\end{array}$ & $\begin{array}{l}64.99 \% \\
(284)\end{array}$ & $\begin{array}{l}32.92 \% \\
(79)\end{array}$ \\
\hline $\begin{array}{l}\text { "I have access to the instruments I need for my } \\
\text { music therapy sessions" }\end{array}$ & $\begin{array}{l}97.52 \% \\
(236)\end{array}$ & $\begin{array}{l}82.38 \% \\
(360)\end{array}$ & $\begin{array}{l}47.92 \% \\
(115)\end{array}$ \\
\hline $\begin{array}{l}\text { "I can carry out most sessions with my clients } \\
\text { without interruptions" }\end{array}$ & $\begin{array}{l}87.60 \% \\
(212)\end{array}$ & $\begin{array}{l}58.81 \% \\
(257)\end{array}$ & $\begin{array}{l}31.67 \% \\
(76)\end{array}$ \\
\hline
\end{tabular}

Table 7

Levels of Agreement with Specific Job Satisfaction Questions

\begin{tabular}{|c|c|c|c|}
\hline Job Satisfaction Question & $\begin{array}{l}\text { High Work } \\
\text { Satisfaction } \\
(n=242)\end{array}$ & $\begin{array}{c}\text { Moderate } \\
\text { Work } \\
\text { Satisfaction } \\
(n=437)\end{array}$ & $\begin{array}{l}\text { Low Work } \\
\text { Satisfaction } \\
(n=240)\end{array}$ \\
\hline $\begin{array}{l}\text { "In my setting I have the opportunity to use the most appro- } \\
\text { priate music therapy interventions for my population" }\end{array}$ & $\begin{array}{l}98.35 \% \\
(238)\end{array}$ & $\begin{array}{l}84.21 \% \\
(368)\end{array}$ & $\begin{array}{l}52.50 \% \\
(126)\end{array}$ \\
\hline $\begin{array}{l}\text { "I can access client records in a timely manner so that I can } \\
\text { assess clients appropriately" }\end{array}$ & $\begin{array}{l}95.45 \% \\
(231)\end{array}$ & $\begin{array}{l}76.66 \% \\
(335)\end{array}$ & $\begin{array}{l}41.25 \% \\
(99)\end{array}$ \\
\hline “I have the opportunity to document my clients' progress" & $\begin{array}{l}97.93 \% \\
(237)\end{array}$ & $\begin{array}{l}87.87 \% \\
(384)\end{array}$ & $\begin{array}{l}62.08 \% \\
(149)\end{array}$ \\
\hline $\begin{array}{l}\text { "I am included in team meetings appropriate to my work du- } \\
\text { ties" }\end{array}$ & $\begin{array}{l}94.63 \% \\
(229)\end{array}$ & $\begin{array}{l}66.13 \% \\
(289)\end{array}$ & $\begin{array}{l}31.67 \% \\
(76)\end{array}$ \\
\hline “My perspective on clients is valued in team meetings" & $\begin{array}{l}91.74 \% \\
(222)\end{array}$ & $\begin{array}{l}67.73 \% \\
(296)\end{array}$ & $\begin{array}{l}30.42 \% \\
(73)\end{array}$ \\
\hline $\begin{array}{l}\text { "I have access to music therapy or creative arts therapy su- } \\
\text { pervision" }\end{array}$ & $\begin{array}{l}61.98 \% \\
(150)\end{array}$ & $\begin{array}{l}34.55 \% \\
(151)\end{array}$ & $\begin{array}{l}15.42 \% \\
(37)\end{array}$ \\
\hline “I have access to non-music therapy supervision at my job" & $\begin{array}{l}75.62 \% \\
(183)\end{array}$ & $\begin{array}{l}58.58 \% \\
(256)\end{array}$ & $\begin{array}{l}30.42 \% \\
(73)\end{array}$ \\
\hline
\end{tabular}

associated with identity development and professional wellbeing (Gamliel et al., 2020; Thaker \& Diambra, 2019).

Reponses to questions related to professional development again highlight disparities between music therapists with high and low satisfaction (Table 8). Indeed, 90.91\% of highly satisfied music therapists reported somewhat or completely agreeing with the statement "I have the same number of learning opportunities (in-services, meetings, lectures, etc.) in my job as my colleagues do," whereas only $56.29 \%$ of music therapists with moderate satisfaction and $19.27 \%$ of music therapists with low satisfaction reported agreement with this statement. Similar levels of disparity were evident in responses to two questions related to financial support, with music therapists with low 
Table 8

Levels of Agreement with Specific Professional Development Questions

\begin{tabular}{|l|l|l|l|}
\hline \multicolumn{1}{|c|}{ Professional Development Question } & $\begin{array}{l}\text { High Work } \\
\text { Satisfaction } \\
(n=242)\end{array}$ & $\begin{array}{c}\text { Moderate } \\
\text { Work } \\
\text { Satisfaction } \\
(n=437)\end{array}$ & $\begin{array}{l}\text { Low Work } \\
\text { Satisfaction } \\
(n=240)\end{array}$ \\
\hline $\begin{array}{l}\text { “I have the same number of learning opportunities (in-ser- } \\
\text { vices, meetings, lectures, etc.) in my job as my colleagues do" }\end{array}$ & $\begin{array}{l}90.91 \% \\
(220)\end{array}$ & $\begin{array}{l}56.29 \% \\
(246)\end{array}$ & $\begin{array}{l}19.17 \% \\
(46)\end{array}$ \\
\hline $\begin{array}{l}\text { "My employer provides financial support to attend at least } \\
\text { one conference a year" }\end{array}$ & $\begin{array}{l}78.10 \% \\
(189)\end{array}$ & $\begin{array}{l}34.10 \% \\
(149)\end{array}$ & $\begin{array}{l}8.33 \% \\
(20)\end{array}$ \\
\hline $\begin{array}{l}\text { "My employer provides financial support for continuing edu- } \\
\text { cation" }\end{array}$ & $\begin{array}{l}78.51 \% \\
(190)\end{array}$ & $\begin{array}{l}35.93 \% \\
(157)\end{array}$ & $\begin{array}{l}11.25 \% \\
(27)\end{array}$ \\
\hline
\end{tabular}

satisfaction reporting very low levels of financial support for conferences and continuing education. These differences appear, once again, to highlight the significant professional challenges music therapists with low satisfaction experience, challenges which may impact their abilities to grow professionally and feel connected to other music therapists. According to Doble and Caron Santha (2008), agency (a sense of control in how and when one engages in one's occupation) and companionship (closeness and connection to others) are important dimensions of occupational wellbeing, dimensions that appear to be distressed for music therapists with low satisfaction.

\section{Stress, Burnout, and Happiness}

Not surprisingly, levels of work satisfaction were strongly associated with levels of stress, burnout, and happiness, with distinct profiles emerging for each satisfaction level. Furthermore, the settings in which music therapists worked were also associated with stress, burnout, and happiness. Music therapists working in medical settings, universities and colleges, hospice, and "other" (a composite work category) experienced the lowest levels of stress and burnout and the highest levels of happiness, whereas music therapists working in older adult/long-term care communities, in mental health settings, and as self-employed/private practice music therapists or as community music therapists experienced the highest stress and burnout and the lowest satisfaction. These distinct workplace experiences are worthy of further investigation, both to more fully understand the features of highly satisfying work settings and to understand the factors that negatively impact a healthy, satisfying work life. It would be, for example, important to understand those factors that are institutional (e.g., when low work satisfaction, high stress and burnout, and low happiness are experienced by the majority of workers in a workplace) and those that are specific to the workplace, job, and professional development experiences of music therapists. Furthermore, understanding the workplace, job, and professional development characteristics of highly satisfying work settings provides a template for advocacy efforts and may inform how music therapy educators prepare their students for professional life. Placing an increased emphasis, for example, on teamwork, interprofessional communication, advocacy for regular and ongoing supervision, and communication with administrators about music therapy's benefits may positively impact the work experiences of music therapists, especially those early in their careers.

\section{Work Satisfaction and Professional Identity}

We also examined written responses to two questions that focused on how respondents thought about being a music therapist ("When I think about being a music therapist, the first thing that comes to mind is...") and on their identity as a music therapist ("When I think about my identity as a music therapist, the first thing that comes to 
mind is...”). Core characteristics of respondents' professional identities were illuminated, providing additional insight into how these identities vary according to work satisfaction. Significantly, across all levels of satisfaction, the music therapists identified as helpers (helping others) who felt pride (passion and pride), gratitude (gratitude, fulfillment, and pride), and fulfillment in their work (satisfaction and fulfillment). Across all levels of work satisfaction, when a negative response was expressed, it focused on advocacy (having to advocate for the profession; misunderstood, advocate, and questioning the value of music therapy; feeling misunderstood, advocacy, and recognition). Across all levels of work satisfaction, when a mixed response was expressed, it focused on feeling misunderstood (misunderstood, advocate, and questioning the value of music therapy; misunderstood and recognition) while also recognizing a positive aspect of the profession.

Different responses to these two questions may also reveal differences in the kinds of challenges music therapists experience in identity development. Music therapists who reported low work satisfaction also reported higher levels of experience being misunderstood, having to advocate for themselves, and feeling self-doubt, shame, failure, and regret. For example, one respondent wrote the following: "I am tired and burned out from advocating for my career and future, and music therapy. I have no opportunity for growth and am undervalued." Music therapists in this quartile were also more likely to report concerns about their salaries when asked about the first thing that comes to mind regarding being a music therapist and were more likely to report a lack of career opportunity. For example, one respondent wrote the following: "I love the work I do when I'm allowed to truly do it but I'm so under-supported in my job. I'm just a glorified activities aide at this point."

In contrast, highly satisfied music therapists reported higher levels of positive comments overall (e.g., Joy; I love music therapy and know that it is my vocation), and while also reporting concerns about feeling misunderstood, advocacy, and recognition, did so at much lower levels than did music therapists with low satisfaction. When concerns were expressed, they were also mitigated by positive aspects of their job. For example, as one respondent explained: "low pay, high level advocacy required, limited job options, but enjoyable, valuable work and I love being a music therapist, I love my job. It is hard some days, and definitely misunderstood."

While understanding the work factors and identity attributes of highly satisfied music therapists provides an educational and policy roadmap for the health of the profession, it also highlights ongoing challenges music therapists experience professionally. Depending on the level of work satisfaction experienced by a music therapist, these challenges may include concerns regarding 1 ) salary (including the ability to secure a full-time position), 2) feeling understood and valued as a professional (advocacy), 3) belonging (feeling part of a community), 4) being able to develop as a professional (supervision, continuing education, conference attendance), and 5) being able to maintain one's health while working as a music therapist (managing stress and burnout).

\section{Occupational Wellbeing}

These findings also invite the music therapy community to think broadly about the occupational wellbeing of the profession. Occupational wellbeing is defined as "a positive evaluation of [...] one's job, including affective, motivational, behavioral, cognitive and psychosomatic dimensions" (van Horne et al., 2004) and as a set of intrinsic needs that characterize one's work experience: agency, accomplishment, affirmation, pleasure, renewal, coherence, and companionship (Doble \& Caron Santha, 2008). While occupational wellbeing as a construct was not specifically investigated in this study, survey data appear to reflect three levels of wellbeing: the work experiences, stress, burnout, happiness, and identities of music therapists who are thriving (high work satisfaction), of those who are moderately satisfied (moderate work satisfaction), and of those who are struggling (low work satisfaction).

Music therapists who reported high work satisfaction appeared to experience, to varying degrees, agency (a sense of control in one's work environment, including one's 
ability to arrange, structure, and implement client/patient sessions in ways one believes are most beneficial to one's clients/patients), accomplishment (identifying strongly as a helper; feeling mastery over one's work), affirmation (feeling satisfied with one's income; pride; feeling passionate about one's work; being valued as a team member), pleasure (fulfillment), renewal (receiving support to attend conferences and continuing education; career development), coherence (good fit), and companionship (feeling part of a team; feeling connected to others). These music therapists tended to report lower levels of stress, lower levels of burnout, and higher levels of happiness compared to music therapists who reported moderate or low work satisfaction.

In contrast, music therapists who reported low work satisfaction appeared to experience, to varying degrees, disruptions to agency (a lack of control in one's work environment, including disruptions to one's ability to arrange, structure, and implement client/patient sessions in ways one believes are most beneficial to one's clients/ patients), accomplishment (feeling challenged), affirmation (feeling dissatisfied with one's income; misunderstood; lacking value as a team member), pleasure (feeling inadequate), renewal (lacking support to attend conferences and continuing education events; lacking support for career development), coherence (disidentifying with music therapy), and companionship (not feeling part of a team; feeling colleagues and administrators do not understand or value one's work). They also tended to report higher levels of stress, higher levels of burnout, and lower levels of happiness compared to music therapists who reported moderate or high work satisfaction. Even with these challenges, however, music therapists who reported low work satisfaction still expressed pride in being a music therapist, passion for their work, gratitude, and a sense of fulfillment, attesting to their resilience and connection to the healing power of music.

\section{Implications for the Profession}

These findings have important implications for the profession and are presented in summary form to promote further discussion:

- Disparate salaries, and the strong association between work satisfaction and salary satisfaction, raise important questions about the perceived value of music therapy, as expressed by employers in the salaries paid to music therapists. Addressing salary variability appears to be an important focus for advocacy efforts at the state and national level.

- The challenges to everyday practice reported by music therapists with low work satisfaction are not only impactful of their work lives but also appear to fundamentally impact their clients. Lack of access to instruments, lack of appropriate session space, and session interruptions warrant immediate attention, given the potential impact on the health and safety of clients.

- Grassroots advocacy, undertaken by music therapists in their everyday work lives, may have limited impact on their overall work lives. Targeted national advocacy efforts by representatives of the profession, especially efforts focused on institutional decision-makers, may be more effective than ad hoc individual advocacy.

- Further examination of the characteristics of highly satisfying workplaces may build a profile of healthy career development and support the occupational wellbeing of the profession. In particular, promoting workplace characteristics that support the dignity of the music therapist and provide an optimal therapeutic environment for clients may advance the profession as a whole.

- Career development appears to be an important topic of conversation for educators and American Music Therapy Association leaders. An examination of how academic programs prepare students for the challenges of professional life and equip them with the tools to address these challenges appears to be important to ensuring the stability and growth of the field. 
- Workplace infrastructures that support regular supervision and promote career development appear to vary considerably across workplaces. Access to supervision and regular, ongoing opportunities for continuing education appear to be central to ensuring the wellbeing of music therapists and to supporting their professional growth.

- A careful examination of the characteristics of music therapy in older adult/longterm care facilities, mental health settings, and private practice appears to be an important undertaking if work conditions in these settings are to be improved.

- Consideration of the profession's growth in terms of occupational wellbeing affirms healthy workplace standards and lifts up the profession as a whole.

- Affirming our identity (identities) as music therapists locates us within educational and healthcare settings in ways that affirm our place in these communities. Celebrating our identity (identities), while also supporting early career professionals as they shape theirs, appears to be central to ensuring the long-term health of the profession.

\section{Conclusion}

Examining the work lives of music therapists by levels of satisfaction provides insight into the workplace, work, and professional development experiences of music therapists who are thriving, of those who are moderately satisfied, and of those who are struggling. The profiles of music therapists who are thriving provide a template for professional growth that advances the wellbeing of the profession. The profiles of music therapists who are struggling offer insight into the challenges the profession faces, while also providing a roadmap for a healthier profession. These profiles ask one to reconsider a) the focus of advocacy efforts, including those concerned with salary equity; b) the extent to which education and training programs prepare students to engage in workplace challenges that improve their work lives; and c) the focus of the profession to ensure its relevance and sustainability.

\section{About the Authors}

Anthony Meadows, PhD, MT-BC, is the Director of Music Therapy at Shenandoah University, Winchester, VA. Correspondence: ameadows2@su.edu

Lillian Eyre, PhD, MT-BC, is Associate Professor of Music Therapy, NTT, at Temple University, Philadelphia, PA.

Audra Gollenberg, PhD, is Professor of Public Health at Shenandoah University, Winchester, VA.

\section{Acknowledgements}

The authors would like to thank Cassie Byers, MMT, MT-BC, for her assistance with data analysis.

\section{Appendix}

Appendix A is available at the following link: https://voices.no/index.php/voices/article/view/3367/3384

\section{References}

Burns, D., \& Masko, M. (2016). Combining interpretivist with objectivist methods in explanatory sequential designs. In B. Wheeler \& K, Murphy (Eds.), Music Therapy Research (3rd ed., pp. 599-607). Barcelona Publishers.

Doble, S., \& Caron Santha, J. (2008). Occupational well-being: Rethinking occupational therapy outcomes. Canadian Journal of Occupational Therapy, 75, 184-187. https://doi.org/ 
Gamliel, K. H., Geller, S., Illuz, B., \& Levy, S. (2020). The contribution of group supervision processes to the formation of professional identity among novice psychotherapists. International Journal of Group Psychotherapy, 70(3), 375-398. http://dx.doi.org/10.1080/ 00207284.2020.1727747

Meadows, A., Eyre, L., \& Gollenberg, A. (2022). Workforce characteristics, workplace and job satisfaction, stress, burnout, and happiness of music therapists in the United States. Voices: A World Forum for Music Therapy. 22(1).

Thacker, N. E., \& Diambra, J. F. (2019). Parallel process of professional identity development during clinical supervision. The Journal of Counselor Preparation and Supervision, 12(3). https://repository.wcsu.edu/jcps/vol12/iss3/6

Saldaña, J. (2016). The coding manual for qualitative researchers (3rd ed.). Sage.

Skorikov, V. B., \& Vondracek, F. W. (2011). Occupational identity. In S. J. Schwartz, K. Luyckx, \& V. L. Vignoles (Eds.), Handbook of identity theory and research, Vols. 1 and 2. (pp. 693-714). Springer Science and Business Media. https://doi-org.suproxy.su.edu/10.1007/ 978-1-4419-7988-9_29

van Horn, J.E., Taris, T.W., Schaufeli, W.B. \& Schreurs, P. (2004). The structure of occupational well-being: A study among Dutch teachers. Journal of Occupational and Organizational Psychology, 77(3), 365-375. https://doi.org/10.1348/0963179041752718

van Saane, N., Sluiter, J., Verbeek J., \& Frings-Dresen, M. (2003). Reliability and validity of instruments measuring job satisfaction: A systematic review. Occupational Medicine, 53(3), 191-200. https://doi.org/10.1093/occmed/kqg038 